\title{
Prognostic Role of Ultrasound Imaging in Desmoplastic Small Round Cell Tumor: A Retrospective Study and Literature Review
}

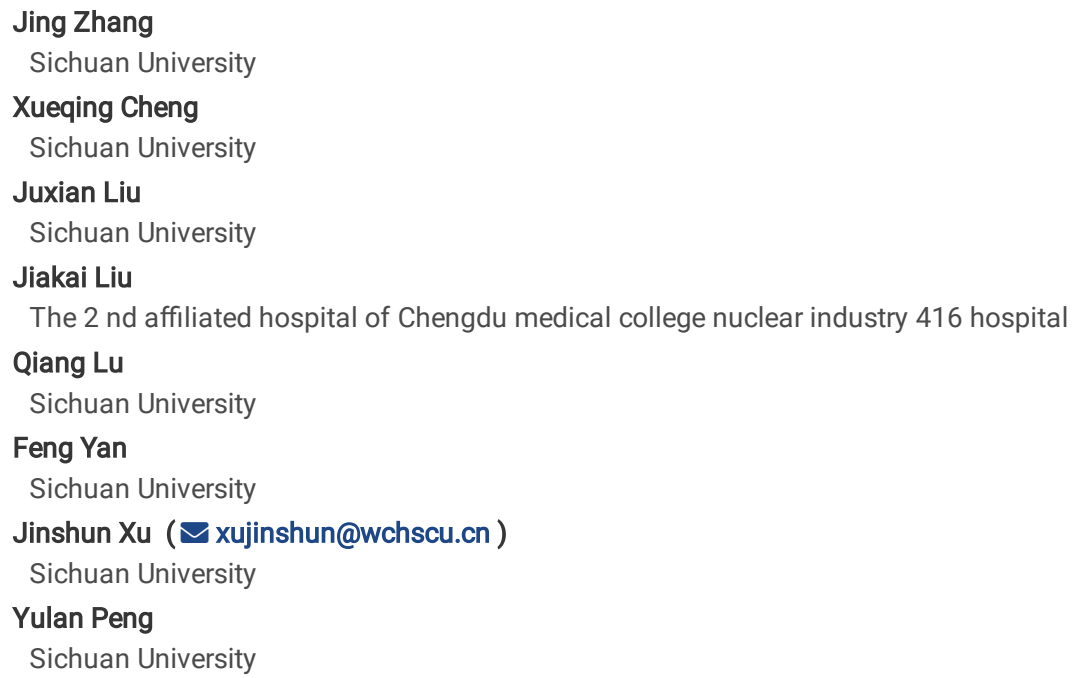




\section{Abstract}

Background: Desmoplastic small round cell tumor (DSRCT) mostly arose in the abdominopelvic cavity is an aggressive sarcoma with poor prognosis. The purpose of this study is to analyze ultrasonographic performance in prediction of prognosis of DSRCT.

Method: Between March 1999 and October 2019, a total of 27 patients with pathologically confirmed DSRCT in our hospital were conducted. Clinical and ultrasonographic characterizations, including age, sex, symptoms, tumor size, number, location, shape, margin, echogenicity, homogeneity, vascularity, and metastases were recorded and analyzed with overall survival (OS) by using univariate analysis.

Result: Ultrasonographic performance of DSRCT were irregular (74\%), posterior echo enhancement (63\%), calcification (51.9\%), and liquefaction (55.6\%) in tumors companied with ascites (63\%), hydronephrosis (59\%) and metastases (63\%). The median OS was 22 months (range 7-36 months) and 5-year OS rate was $19.6 \%$. Using univariate analysis, a higher hazard ratio (HR) of mortality was associated with liquefaction (HR: 3.09, 95\% Cl:1.23-7.76, $p=0.016)$ and bone metastasis (HR: $2.95,95 \% \mathrm{Cl}: 1.16-7.49, p=0.023$ ). According to a risk staging system developed by selected predictors (low = neither liquefaction nor bone involvement; moderate = either liquefaction or bone involvement; high = both liquefaction and bone involvement), 40\%, 10\%, and 0 of 3 -year survival were found in the low, moderate, and high risk patients, respectively.

Conclusion: Ultrasound imaging is effective to evaluate prognosis of DSRCT. Findings of liquefaction and bone involvement in the ultrasonography may predict a poor prognosis of DSRCT patients.

\section{Introduction}

Desmoplastic small round cell tumor (DSRCT) is a rare but highly aggressive soft tissue sarcoma that arises most commonly in the abdominopelvic cavity of males in adolescence or young adulthood [1,2]. Since it is a high-grade neoplasm often presenting with advanced disease, the successful surgical excisions are extremely rare $[3,4]$. To date, there have been no reports of patients benefiting from postoperative radio/chemotherapy. The median survival of DSRCT is less than 3 years, and the 5 -year survival was less than $15 \%[5,6]$. Therefore, it is urgent to explore the risk factors for prediction of DSRCT prognosis.

Owing to the absence of valid clinical characterizations and specific laboratory indicators of DSRCT, CT, MRI, and PET-CT imaging techniques play an important role in describing tumor extension, identifying multicentric lesions or local recurrences, and evaluating disease progression and treatment outcomes [7-9]. However, due to the radiation, high cost and inconvenient operation, these imaging methods are not suitable for early large-scale and routine screening of DSRCT, especially for pregnant women and adolescents. Since ultrasonography has no radiation, good accessibility and low cost for common diagnosis, preoperative guidance, intraoperative localization and following-up [10-12], it might be useful on prediction of DSRCT prognosis.

Most of the literatures on DSRCT has focused on the evaluation of pathological diagnosis and treatment outcomes [2, 9, 13, 14]. However, the detailed ultrasonographic manifestations have not been reported, to the best of our knowledge. Furthermore, almost all the patients with DSRCT reported are from Europe and America, studies focused on Asian patients with DSRCT have been merely publication. Herein, 27 cases of abdominopelvic DSRCT from China treated in our hospital were analyzed retrospectively and ultrasound imaging features were summarized in the study, in order to predict the prognosis of DSRCT.

\section{Materials And Methods Study design}

The data of DSRCT patients treated in our hospital from March 1999 to October 2019 were collected and analyzed with the approval of the institutional Review Committee. All clinical characterizations and ultrasonic images were included in this study. Pathologic data from the medical records were gathered to confirm the diagnosis. Cases were excluded if sufficient clinical data and/or ultrasonographic characterizations was unavailable. We obtained data on patient demographics, clinical presentation, diagnostic information, and survival. Written informed consent was waived because of the retrospective nature of clinical and imaging data collection.

\section{Ultrasonography}

Ultrasound was performed using 3-8 MHz curvilinear transducer on ultrasound machines (Philips IU 22, Netherlands; LOGIQ E9, USA). For each examination, the total abdominopelvic scanning was performed, including liver, spleen, pancreas, kidney, ureter, bladder, vertebra and ilium, lymph nodes and vessels in peritoneum and retroperitoneum. Tumor size, number, location, shape, margin, echogenicity, homogeneity, and vascularity of the lesion as well as the distribution pattern of metastases were analyzed. The vascularization of tumor was determined by color Doppler technique based on Adler grade classifications [15]. Additionally, peritoneal and retroperitoneal lymph nodes, abdominal effusion, and adjacent organs were also examined.

\section{Definition}

Overall survival (OS) was defined as the time from diagnosis to the most recent imaging examination of patient or patient death. Liquefaction was defined as central necrosis or hemorrhage due to the rapid growth and insufficient blood supply of the tumor, which was presented with cystic components on ultrasonography. The ultrasonography performances of bone metastases were defined as local homogeneous or heterogeneous hypoechoic zone beside bone with thinning and (or) discontinuity of bone cortex as a result of the tumor erosion.

\section{Pathology Assay}


Using biopsy, diagnosis confirmation was required based on histopathological features, polyphenotypic immunohistochemical reactivity, and molecular/cytogenetic findings. Immunohistochemistry was performed on using standard techniques. Markers variably included pancytokeratin (AE1/AE3; 1:175; DAKO), smooth muscle actin (1A4; 1:200; DAKO), vimentin (V9; 1:200; DAKO), CD99 (EPR3097Y; 1:50; Cell Marque), neuron specific enolase (BBS/NC/VI-H14; 1:600; DAKO). Molecular confirmation was accomplished using fluorescence in situ hybridization (FISH).

\section{Treatment and follow up}

Combination therapy strategies (systemic chemotherapy, preoperative chemotherapy, intraperitoneal chemotherapy, radiotherapy, surgery) were performed for the DSRCT patients. The therapeutic options and sequence were systematically discussed in a multidisciplinary team meeting. Ultrasound was performed 1,3 , 6,9 and 12 months after initial systemic chemotherapy/surgery and at 3-6-month intervals thereafter. Follow-up period was recorded as the time from initial treatment to the most recent imaging examination.

\section{Statistical analysis}

Statistical analyses were performed on SPSS 25 software (IBM, NY, USA). Data were expressed as median with the interquartile range (IQR) and percentage unless otherwise stated. Annual and median survival estimates were provided along with $95 \%$ confidence interval (Cl) and Kaplan-Meier (KM) plots. Survival analyses were conducted by the Kaplan-Meier method and compared with log-rank test. Cox regression models were used to estimate the hazard ratio (HR) of overall survival (OS) according to patient, tumor, and ultrasonographic findings. HRs were presented with $95 \% \mathrm{Cl}$ and statistical significance was defined as $p$ value $<0.05$.

\section{Results}

\section{Clinical characterization}

A total of 41 patients with DSRCT diagnosed during this period were identified. Of these, 27 patients had complete imaging data and were included in the study. As shown in Table 1, a predominance of young male patients (22 males vs 5 females; median age 21.5 years; range 18-42 years) were found. The most common presenting symptoms in the 27 DSRCT cases were abdominal pain in 11 (40.7\%) and abdominal distention in 9 (33.3\%).

Table 1

Clinical characteristics of 27 patients with DSRCT

\begin{tabular}{|ll|}
\hline Characteristic & Value (\%) \\
\hline Age(year & \\
median & 21.5 \\
range & $18-42$ \\
Sex & \\
$\quad$ male & $22(81.5)$ \\
female & $5(18.5)$ \\
Presenting clinical features & \\
palpable abdominal mass & $8(29.6)$ \\
abdominal pain & $11(40.7)$ \\
abdominal distention & $9(33.3)$ \\
abdominal discomfort & $7(25.9)$ \\
constipation & $4(14.8)$ \\
\hline
\end{tabular}

Table 2

US characterization of DSRCT in the 27 patients 


\begin{tabular}{|ll|}
\hline US characterization & NO. of patients (\%) \\
Location & $10(37)$ \\
upper abdomen & $8(29.6)$ \\
full abdomen & $9(33.4)$ \\
No. of lesions & \\
$<3$ & $7(25.9)$ \\
$\geq 3, \leq 5$ & $11(40.7)$ \\
$>5$ & $9(33.4)$ \\
Metastases & $10(37.0)$ \\
liver & $9(33.3)$ \\
lymph node & $7(25.9)$ \\
vertebra and (or) ilium & \\
Ascites & $12(44.4)$ \\
small-moderate & $5(18.5)$ \\
large & \\
Hydronephrosis & \\
unilateral & \\
bilateral & $(37)$ \\
\hline
\end{tabular}

\section{Ultrasound features}

Abdominal ultrasound findings of patients were summarized in Table 2. The most representative trait in DSRCT was that no definite organ origin was found in all the soft-tissue masses. In our cohort, the sizes of multiple masses in patients varied from 3.5 to $11.8 \mathrm{~cm}$ (median, $7.2 \mathrm{~cm}$ ) in the maximum diameter, as shown in Figure 1A. 17 (63\%) of patients presented with metastases involved in liver, lymph node, and bone (Figure 1B). Concurrent metastasis in liver was identified in $10(37.0 \%)$ patients, with a median size of $3.2 \mathrm{~cm}$ in diameter (Figure 1C). The lymph node metastasis was found in 9 (33.3\%) patients and 7 (25.9\%) patients had destructive erosion of vertebra and (or) ilium, suggesting the existence of bone metastasis. However, no significant invasion of adjacent vessels was found. In addition, 16 (59.3\%) patients manifested unilateral/bilateral hydronephrosis caused by the oppression from masses (Figure 1D). A small to moderate amount of ascites was found in 12 (44.4\%) patients and large ascites were presented in 5 (18.5\%) patients (Figure 1E).

Ultrasonographic findings of the abdominopelvic DSRCT were shown in Table 3. The margins of all the masses were not well-defined, as presented in slur (44.4\%), lobular (40.7\%), and spiculate (14.8\%). The majority of masses were presented with irregular in shape (74.1\%), posterior echo enhancement (63\%), micro/coarse calcification (51.9\%), and liquefaction (55.6\%) (Figure 2). 13 (48.1\%) of the masses were homogeneous/heterogeneous hypoechoic and no significant traits of vascularity were found based on Adler grade system. To express straightforward, one of the most representative cases was shown in Figure 3.

Table 3

US features of the masses in the 27 patients with DSRCT 


\begin{tabular}{|c|c|}
\hline B-mode US features & NO. of tumors (\%) \\
\hline \multicolumn{2}{|l|}{ Shape } \\
\hline quasi-round or elliptic & $7(25.9)$ \\
\hline irregular & $20(74.1)$ \\
\hline \multicolumn{2}{|l|}{ Margin } \\
\hline well-defined & $0(0)$ \\
\hline slur & $12(44.4)$ \\
\hline lobular & $11(40.7)$ \\
\hline spiculate & $4(14.8)$ \\
\hline \multicolumn{2}{|l|}{ Echogenicity } \\
\hline anecho & $0(0)$ \\
\hline hypoecho & $13(48.1)$ \\
\hline isoecho & $5(14.8)$ \\
\hline hyperecho & $0(0)$ \\
\hline mix-echo & $9(33.3)$ \\
\hline \multicolumn{2}{|l|}{ Posterior echo } \\
\hline Attenuation & $5(18.5)$ \\
\hline Enhancement & $17(63.0)$ \\
\hline Unaltered & $2(7.4)$ \\
\hline mix-altered & $3(11.1)$ \\
\hline \multicolumn{2}{|l|}{ Calcification } \\
\hline coarse calcification & $8(29.6)$ \\
\hline microcalcification & $6(22.2)$ \\
\hline \multicolumn{2}{|l|}{ Liquefaction } \\
\hline present & $15(55.6)$ \\
\hline absent & $12(44.4)$ \\
\hline \multicolumn{2}{|l|}{ Vascularity (Adler grade) } \\
\hline 0 & $0(0)$ \\
\hline I & $10(37)$ \\
\hline II & $11(41)$ \\
\hline III & $6(22)$ \\
\hline
\end{tabular}

\section{Pathologic Features}

One of the representative cases in microscopic analysis demonstrated clumps of small round cells with hyperchromatic nuclei and small eosinophilic cytoplasm, surrounded by a hypocellular desmoplastic, collagenous stroma (Figure 4). Immunohistochemistry was performed in 25 cases. Of these, 20 cases showed some degree of immunoreactivity in cytokeratin ranging from focal to diffuse. CD99 ranged from weak to diffuse in 14 of the 23 cases. Both FL1 and WT-1 markers tested in 19 cases were positive.

\section{Treatment outcome and follow-up}

In the cohort study, all the patients received systemic chemotherapy and 20 (74.1\%) patients underwent surgery. In order to achieve the maximum resection, 13 (48.1\%) patients accepted preoperative chemotherapy to shrink masses. Besides, the whole abdomen radiotherapy was performed in 3 (11.1\%) patients before resection and postoperative intraperitoneal chemotherapy was carried out in 8 (29.6\%) patients.

After a median follow-up of 30 months (range 7-78 months), the median overall survival (OS) of the entire cohort was 26 months (95\%Cl: $21.1-30.9$ months). 21 patients had died by the end of the follow up and 6 patients were alive with disease progression. The one-, two-, and five-year OS rates after diagnosis were $92.6 \%, 54.7 \%$, and $19.5 \%$, respectively (Figure $5 \mathrm{~A}$ ). 
Predictive factors for overall survival in patients with desmoplastic round cell tumor $(\mathrm{N}=27)$

\begin{tabular}{llll} 
Variable & $\mathrm{HR}$ & $95 \% \mathrm{Cl}$ & P-value \\
\hline Age $\geq 20 \mathrm{y}$ & 1.0 & $0.3-3.1$ & 0.9 \\
\hline Liver metastasis & 1.7 & $0.7-4.0$ & 0.2 \\
\hline lymph node metastasis & 1.7 & $0.7-4.1$ & 0.2 \\
\hline Bone metastasis & 2.9 & $1.2-7.5$ & $0.023^{*}$ \\
\hline Ascites & 1.7 & $0.9-3.2$ & 0.1 \\
\hline Shape & 2.1 & $0.7-6.4$ & 0.2 \\
\hline Margin & 1.8 & $0.8-4.5$ & 0.2 \\
\hline Posterior echo enhancement & 2.0 & $0.7-5.3$ & 0.2 \\
\hline Calcification & 2.0 & $0.8-4.9$ & 0.1 \\
\hline Liquefaction & 3.1 & $1.2-7.8$ & $0.016^{*}$ \\
\hline
\end{tabular}

Abbreviations: $95 \% \mathrm{Cl}, 95 \%$ confidence interval; HR, hazard ratio.

To assess the correlation between clinical and ultrasonographic characterizations, the univariate analysis was performed (Table 4). The higher risks of mortality were found in tumor with liquefaction (HR: 3.1, 95\% Cl:1.2-7.8) and bone metastasis (HR: 2.9, 95\% Cl: 1.2-7.5), resulting in the lower median 0S than those without (20.1 vs 26.0 months for liquefaction; 18.8 vs 23.8 months for bone metastasis) (Figure $5 \mathrm{~B}-\mathrm{C}$ ).

Based on the selected mode, a risk staging system was developed: patients with both liquefaction and bone involvement were assigned in the high risk stage, patients with either liquefaction or bone involvement were assigned in the moderate risk stage, and patients with neither liquefaction nor bone involvement were assigned in the low risk stage. In the existing dataset, 10 patients had low risk, 11 patients had moderate risk, and 6 patients had high risk. The 3-year survival of $40 \%$ was found in low risk patients versus $10 \%$ among moderate risk patients and 0 among high risk patients (Figure 5D).

\section{Discussion}

DSRCT is initially described by Gerald and Rosai in 1989 [16] with an annual incidence of less than 0.5 per million [1, 4]. This tumor primarily originates from the serosal surfaces of the abdominal and pelvic cavity, showing the characteristic $t(11 ; 22)(p 13 ; q 12)$ chromosomal translocation and gene fusion between Ewing sarcoma (EWS) and Wilms tumor (WT1) [17-19]. According to literature reports, DSRCT patients in Europe and America are mostly male, with a sex ratio as high as 3:1 9:1 [5, 20,21]. In our cohort, the patients from China showed consistent ratio of 4:1 (males to females), confirming the dominance of males in the disease.

The manifestations of DSRCT are non-specific: the large, palpable abdominal masses are presented in most patients with or without vague abdominopelvic discomfort including distension, pain or change in bowel habits accompanied with weight loss, or symptoms related to metastases [2], as shown in 87\% of patients in the present study. Since the diagnosis of DSRCT in the early stage is difficult, most patients with DSRCT come to clinical attention until it is large enough to compress or invade surrounding structures, such as the obstruction of bowel loops and (or) urinary system [3,5]. In the present study, 16 (59.3\%) patients present with bilateral/unilateral hydronephrosis resulting from obstructing pelvic masses, but no patients present with bowel obstruction.

Imaging features of DSRCT on cross-sectional modalities including CT, MRI and PET/CT have been reported [8]. However, as one of the most prevalent options for imaging examination, ultrasonography might contribute to positive evidence for DSRCT prognostic prediction but limited publication. Through literature review, the DSRCT reports on ultrasound performance have been summarized in Table 5. The majority (73\%) of publications are case reports and none of them highlighted in the ultrasonography of DSRCT. In the latest two cohort analyses, imaging patterns of this disease on CT and MRI have been reported in detail, while ultrasonography characterization is limited description $[13,14]$. Comparatively, this study focuses on ultrasonography features to analyze the prognostic role of ultrasound imaging in DSRCT patients.

Table 5

Summary of literatures regarding ultrasonography performance of DSRCT 


\begin{tabular}{|c|c|c|c|c|c|c|c|c|c|}
\hline \multirow[t]{2}{*}{ Author } & \multirow[t]{2}{*}{ Year } & \multirow[t]{2}{*}{ Nation } & \multirow{2}{*}{$\begin{array}{l}\text { Patient } \\
\text { No. }\end{array}$} & \multirow[t]{2}{*}{ Article type } & \multirow[t]{2}{*}{ Main focus } & \multicolumn{4}{|c|}{ Ultrasonography performance } \\
\hline & & & & & & Margin & Echogenicity & Vascularity $^{*}$ & Liquefaction/Calcificatior \\
\hline $\begin{array}{l}{ }^{[9]} \text { Pickhardt, } \\
\text { et al. }\end{array}$ & 1999 & USA & 14 & $\begin{array}{l}\text { Retrospective } \\
\text { study }\end{array}$ & Imaging/pathology & $\begin{array}{l}\text { well- } \\
\text { defined }\end{array}$ & hypoechoic & / & -- \\
\hline [22] Kim, et al. & 2003 & Korea & 2 & Case report & CT imaging & / & / & internal & ++ \\
\hline $\begin{array}{l}{ }^{[23]} \text { Gorospe, } \\
\text { et al. }\end{array}$ & 2007 & Spain & 1 & Case report & MRI imaging & / & / & / & +- \\
\hline $\begin{array}{l}{[24] \text { Kandhari, }} \\
\text { et al. }\end{array}$ & 2015 & India & 1 & Case report & Diagnosis/treatment & $\begin{array}{l}\text { ill- } \\
\text { defined }\end{array}$ & variable & / & -1 \\
\hline $\begin{array}{l}\text { [20] Shen, et } \\
\text { al. }\end{array}$ & 2014 & China & 4 & Case report & Clinical/CT imaging & / & hypoechoic & rim & +1 \\
\hline $\begin{array}{l}\text { [25] Chen, et } \\
\text { al. }\end{array}$ & 2015 & China & 2 & Case report & Diagnosis & / & / & / & -1 \\
\hline $\begin{array}{l}\text { [26] Eklund, et } \\
\text { al. }\end{array}$ & 2015 & USA & 1 & Case report & Diagnosis (CT, US) & I & / & rim & -1 \\
\hline $\begin{array}{l}{ }^{[27]} \text { Karim, et } \\
\text { al. }\end{array}$ & 2018 & Tunisia & 1 & Case report & Diagnosis/treatment & $\begin{array}{l}\text { ill- } \\
\text { defined }\end{array}$ & hypoechoic & absent & -1 \\
\hline $\begin{array}{l}{ }^{[13]} \text { Morani, et } \\
\text { al. }\end{array}$ & 2019 & USA & 94 & $\begin{array}{l}\text { Retrospective } \\
\text { study }\end{array}$ & Diagnosis & $\begin{array}{l}\text { ill- } \\
\text { defined }\end{array}$ & hypoechoic & vascular & ++ \\
\hline $\begin{array}{l}{ }^{[14]} \text { LaQuaglia, } \\
\text { et al }\end{array}$ & 2020 & USA & 130 & $\begin{array}{l}\text { Retrospective } \\
\text { study }\end{array}$ & Imaging/survival & / & / & / & / \\
\hline
\end{tabular}

US=ultrasonography; $\mathrm{CT}=$ computed tomography; $\mathrm{MRI}=$ magnetic resonance imaging; $\mathrm{PET} / \mathrm{CT}=$ =positron emission tomography

*Vascularity was categorized as absent, vessels in rim (rim), and internal vascularity (internal).

\# Liquefaction/Calcification were classified as positive (+) and negative (-).

On ultrasonography, the echogenicity of masses ranges from hypoechoic to hyperechoic. Most of the early tumors show hypoechoic followed by echogenic enhancement in the middle and later stages, as a result of pathological progression of tumor cells and stroma, such as hemorrhage, fibrosis, and necrosis [22]. In the study, almost half of the masses are homogeneous/heterogeneous hypoechoic, which could be one of the typical features for the diagnosis of DSRCT. Interestingly, owing to the rapid tumor growth and insufficient blood supply, liquefaction is shown in 15 (55.6\%) patients, which have an increased risk and reduced OS compared to those without (20.1 vs 26.0 months, $p=0.016)$. Moreover, posterior echo enhancement is found in 17 ( $63.0 \%)$ patients, which could be used as another typical feature for the diagnosis of DSRCT. Although conflicting data regarding the presence of calcification in abdominopelvic DSRCT were reported on several prior publications $[20,23], 14$ patients $(51.9 \%)$ with micro/coarse calcification is revealed in our series, indicating that calcification is a relatively common radiological trait in DSRCT. In addition, all the masses are ill-defined in margin and no specific manifestations in the vascularity based on Adler grade system. Collectively, the combination of imaging factors including heterogeneous hypoechoic, ill-defined in margin, posterior echo enhancement, and presence of calcification and liquefaction within the masses might attribute to DSRCT diagnosis on ultrasonography.

Metastasis is found in 17 (63\%) patients involving enlarged lymph nodes, hematogenous dissemination, and direct invasion of liver and skeletons. The incidence of metastasis in our series is consistent with those reported previously among $31 \%$ to $80 \%[5,24]$ with liver as the main metastatic target of DSRCT [7]. In this work, the hepatic metastases featured with well-defined margins and hypoechoic halo surrounding the lesions are found in 10 (37.0\%) patients, which are more common than those in the involvement of lymph and skeletons.

Despite use of multidisciplinary treatment combination, a poor prognosis with a 5 -year survival of $19.6 \%$ was found in our study. This is similar to the results of previous reports $[5,25,26]$. Through the development of a risk staging system based on the survival predictors of liquefaction and bone involvement, prominent intervals in 3-year survival were found between low (40\%), moderate (10\%), and high (0) risk patients. We believe that this system could contribute to management and prognosis of this patients. Given that the risk staging system was developed in the cohort patients with limited quantity, external validation with large amounts of patients are necessary to evaluate statistical differences among these groups.

Our study has certain limitations. First of all, due to the low prevalence of the disease, especially in Asian, the deficiency of sample size reduces accuracy of statistical analysis. Secondly, the inherent biases in retrospective cohort study are accompanied inevitably. Thirdly, our study was conducted in single center, which may be limited by our own ultrasound experience. Lastly, all the patients enrolled are from southwest of China, which may not be generalization to the Asian patients with DSRCT in all sites. Therefore, these results need further verification.

In conclusion, this study summarizes the overall ultrasonography characteristics in a cohort of DSRCT patients, along with the comprehensive literature review. Based on the survival predictors of liquefaction and bone involvement induced by univariate analysis, a risk-staging system was developed and exhibited a prognostic role in DSRCT. 


\section{Declarations}

\section{Ethics approval and consent to participate}

Ethical approval was approved by the Institutional Review Committee of our hospital and written informed consent was waived due to the retrospective nature of clinical and imaging data collection.

\section{Consent for publication}

Not applicable.

\section{Competing interests}

The authors declare no competing interests.

\section{Funding}

The 1.3.5 project for disciplines of excellence, West China Hospital, Sichuan University (ZYJC18008); Beijing Natural Science Foundation (7192200); Science and Technology Project of Chengdu (2019-YF05-00376-SN, 2017-CY02-00027-GX); Science and Technology Project of the Health Planning Committee of Sichuan (20PJ011).

\section{Author contributions}

J.Z., X.C., J.X. and Y.P. have full access to all the data and take responsibility for the integrity of this study. J.L., J.X., F.Y., and Y.P. contributed to the conception and study design. J.Z., J.L. performed the data collection and analyses. J.Z. and X.C wrote the draft of the manuscript. J.Z., X.C., and J.L. prepared figures 1-5. J.X., F.Y., Q.L. and Y.P. finished the critical revision of the manuscript. All authors reviewed to final versions of the article and approved the submission.

\section{Acknowledgements}

Not applicable.

\section{Availability of data and materials}

The raw data analyzed in this study can be accessed by contacting xujinshun@wchscu.cn.

\section{References}

1. Mir O, Adam J, Honoré C: Optimal Multimodal Treatment for Desmoplastic Small Round Cell Tumors. JAMA Oncol 2018, 4(9):1301.

2. Stiles ZE, Dickson PV, Glazer ES, Murphy AJ, Davidoff AM, Behrman SW et al: Desmoplastic small round cell tumor: A nationwide study of a rare sarcoma. J Surg Oncol 2018, 117(8):1759-1767.

3. Hayes-Jordan A, Anderson PM: The diagnosis and management of desmoplastic small round cell tumor: a review. Curr Opin Oncol 2011, 23(4):385-389.

4. Mora J, Modak S, Cheung NK, Meyers P, de Alava E, Kushner B et al: Desmoplastic small round cell tumor 20 years after its discovery. Future Oncol 2015, 11(7):1071-1081

5. Angarita FA, Hassan S, Cannell AJ, Dickson BC, Gladdy RA, Swallow CJ et al: Clinical features and outcomes of 20 patients with abdominopelvic desmoplastic small round cell tumor. Eur J Surg Oncol 2017, 43(2):423-431.

6. Gani F, Goel U, Canner J, Meyer C, Johnston F: A national analysis of patterns of care and outcomes for adults diagnosed with desmoplastic small round cell tumors in the United States. Journal of surgical oncology 2019, 119(7):880-886.

7. Gorospe L, Gomez T, Gonzalez LM, Lopez A: Desmoplastic small round cell tumor of the pelvis: MRI findings with histopathologic correlation. Eur Radiol 2007, 17(1):287-288.

8. Zhang WD, Li CX, Liu QY, Hu YY, Cao Y, Huang JH: CT, MRI, and FDG-PET/CT imaging findings of abdominopelvic desmoplastic small round cell tumors: correlation with histopathologic findings. Eur J Radiol 2011, 80(2):269-273.

9. Pickhardt PJ, Fisher AJ, Balfe DM, Dehner LP, Huettner PC: Desmoplastic small round cell tumor of the abdomen: radiologic-histopathologic correlation. Radiology 1999, 210(3):633-638.

10. Ferreira AC, Costa FS, Reis Neto AJ, Alcantara KB, Jordão JF, Faria RCS: Focal Nodular Hyperplasia During Acute Abdomen Ultrasound Diagnosis and Correlation With Computed Tomography and Magnetic Resonance During an Acute Abdomen. Ultrasound in Medicine \& Biology 2013, 39(5).

11. Oh HC, Seo DW: Ablate under EUS-guidance when properly indicated. Gastroenterology 2011, 141(2):e20-21. 
12. Harvey SC, Wolff AC: Does a Picture Make a Difference? Ultrasound Guidance in the Management of the Axilla After Neoadjuvant Chemotherapy. J Clin Oncol 2015, 33(30):3367-3369.

13. Morani AC, Bathala TK, Surabhi VR, Yedururi S, Jensen CT, Huh WW et al: Desmoplastic Small Round Cell Tumor: Imaging Pattern of Disease at Presentation. AJR Am J Roentgenol 2019, 212(3):W45-W54.

14. Saltsman JA, 3rd, Price AP, Goldman DA, Hammond WJ, Danzer E, Magnan H et al: A novel image-based system for risk stratification in patients with desmoplastic small round cell tumor. J Pediatr Surg 2020, 55(3):376-380.

15. Adler DD, Carson PL, Rubin JM, Quinn-Reid D: Doppler ultrasound color flow imaging in the study of breast cancer: preliminary findings. Ultrasound Med Biol 1990, 16(6):553-559.

16. Gerald WL, Miller HK, Battifora H, Miettinen M, Silva EG, Rosai J: Intra-abdominal desmoplastic small round-cell tumor. Report of 19 cases of a distinctive type of high-grade polyphenotypic malignancy affecting young individuals. Am J Surg Pathol 1991, 15(6):499-513.

17. de Alava E, Marcilla D: Birth and evolution of the desmoplastic small round-cell tumor. Semin Diagn Pathol 2016, 33(5):254-261.

18. Gedminas J, Chasse M, McBrairty M, Beddows I, Kitchen-Goosen S, Grohar P: Desmoplastic small round cell tumor is dependent on the EWS-WT1 transcription factor. Oncogenesis 2020, 9(4):41.

19. Lee SB, Kolquist KA, Nichols K, Englert C, Maheswaran S, Ladanyi M et al: The EWS-WT1 translocation product induces PDGFA in desmoplastic small round-cell tumour. Nat Genet 1997, 17(3):309-313.

20. Shen XZ, Zhao JG, Wu JJ, Liu F: Clinical and computed tomography features of adult abdominopelvic desmoplastic small round cell tumor. World J Gastroenterol 2014, 20(17):5157-5164.

21. Honore C, Delhorme JB, Nassif E, Faron M, Ferron G, Bompas E et al: Can we cure patients with abdominal Desmoplastic Small Round Cell Tumor? Results of a retrospective multicentric study on 100 patients. Surg Oncol 2019, 29:107-112.

22. Iyer RS, Schaunaman G, Pruthi S, Finn LS: Imaging of pediatric desmoplastic small-round-cell tumor with pathologic correlation. Curr Probl Diagn Radiol 2013, 42(1):26-32.

23. Kim JH, Goo HW, Yoon CH: Intra-abdominal desmoplastic small round-cell tumour: multiphase CT findings in two children. Pediatr Radiol 2003 , 33(6):418-421.

24. Hayes-Jordan A, Green HL, Lin H, Owusu-Agyemang P, Fitzgerald N, Arunkumar R et al: Complete Cytoreduction and HIPEC Improves Survival in Desmoplastic Small Round Cell Tumor. Annals of Surgical Oncology 2013, 21(1):220-224.

25. Scheer M, Vokuhl C, Blank B, Hallmen E, von Kalle T, Münter M et al: Desmoplastic small round cell tumors: Multimodality treatment and new risk factors. Cancer medicine 2019, 8(2):527-542.

26. Hayes-Jordan A, Green H, Lin H, Owusu-Agyemang P, Fitzgerald N, Arunkumar R et al: Complete cytoreduction and HIPEC improves survival in desmoplastic small round cell tumor. Annals of surgical oncology 2014, 21(1):220-224.

\section{Figures}




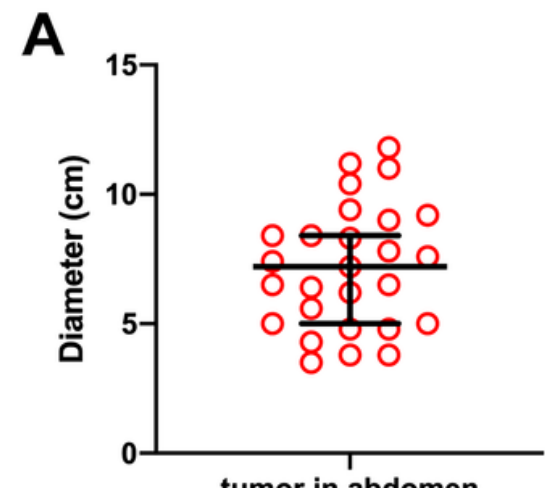

tumor in abdomen
C

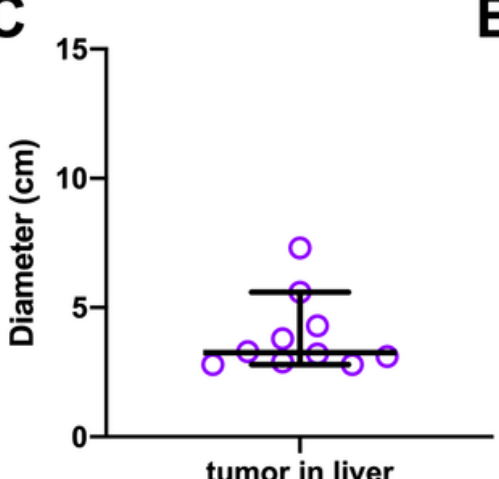

tumor in liver
B

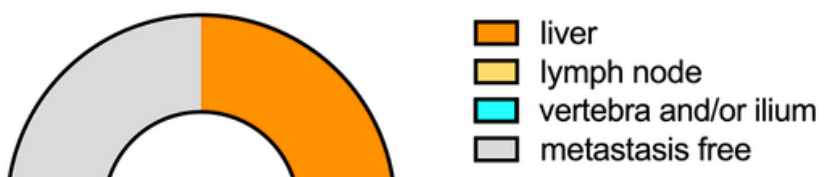

D

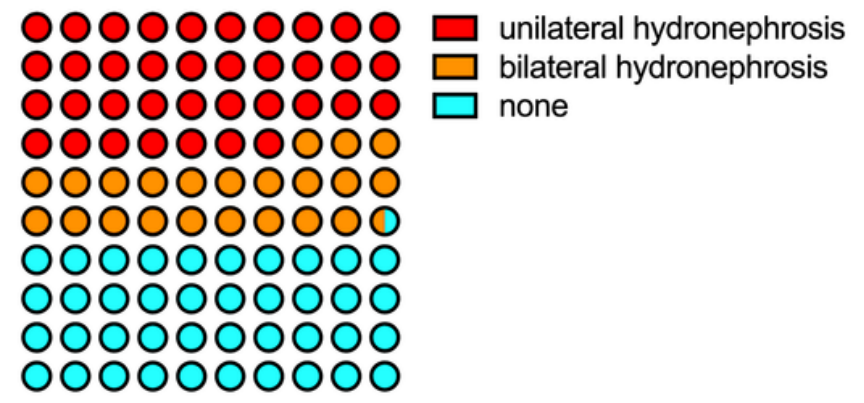

Total=27
E

$0000000000 \square$ large ascites $0000000000 \square$ low-medium ascites O०00000000 $\square$ none 0000000000 0000000000 0000000000 0000000000 0000000000

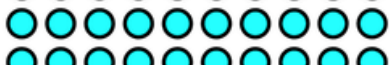
O०००००००००

Total $=\mathbf{2 7}$

Figure 1

The abdominal ultrasound findings of DSRCT including tumor sizes in abdomen (A) and liver (C), metastasis (B), hydronephrosis (D), ascites (E). 


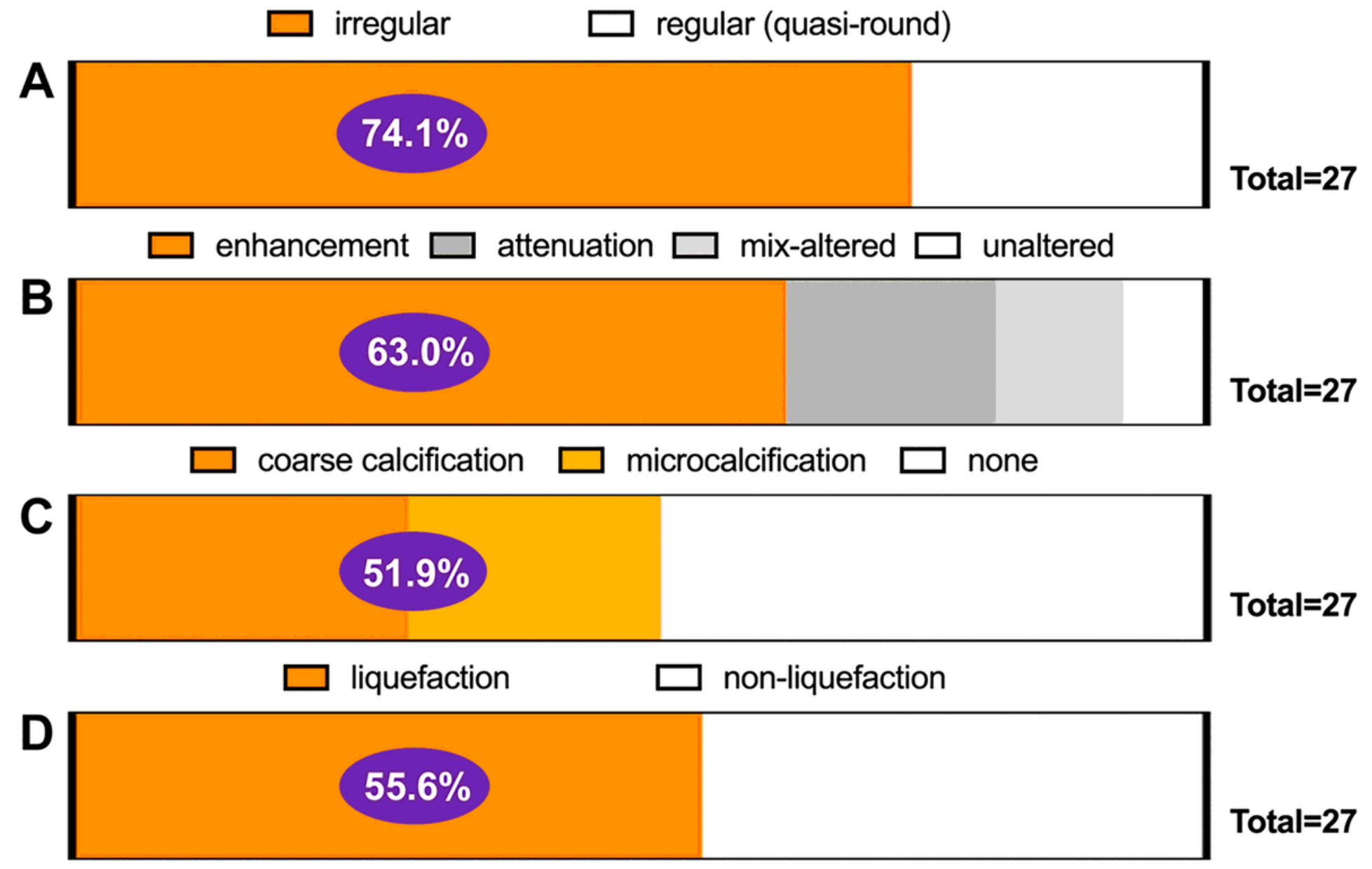

Figure 2

Ultrasonography performance of the abdominopelvic DSRCT including shape(A), posterior echo(B), calcification(C), liquefaction(D). 

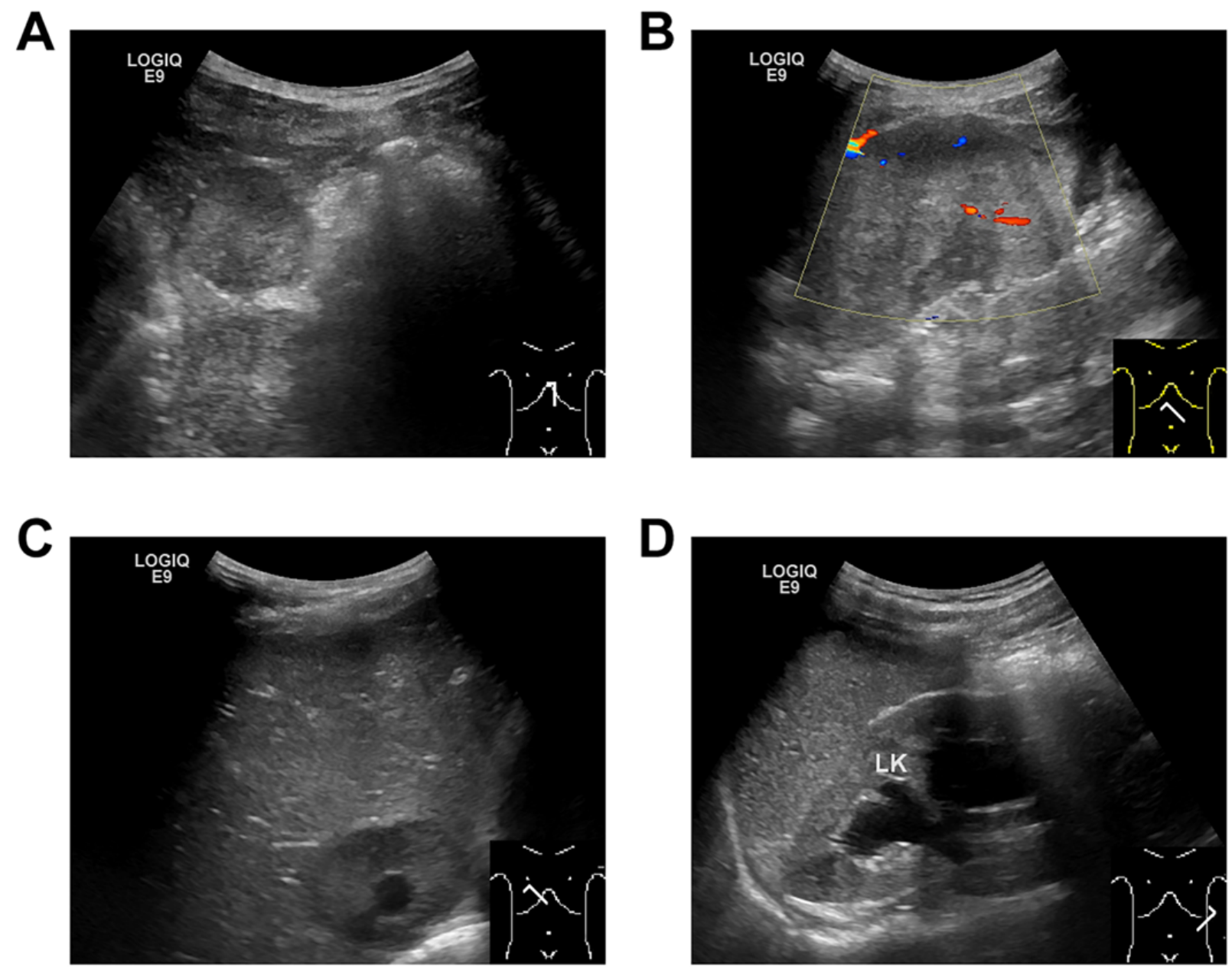

\section{Figure 3}

The ultrasonography features in one representative case (A 19-year-old man with abdominopelvic DSRCT). B-Mode ultrasonography showed that the mass was hypoechoic with irregular in shape (A), rough in margin and post echo enhancement (B), cystic degeneration in parenchyma (C), and accompanied with hydronephrosis in left kidney (D). 


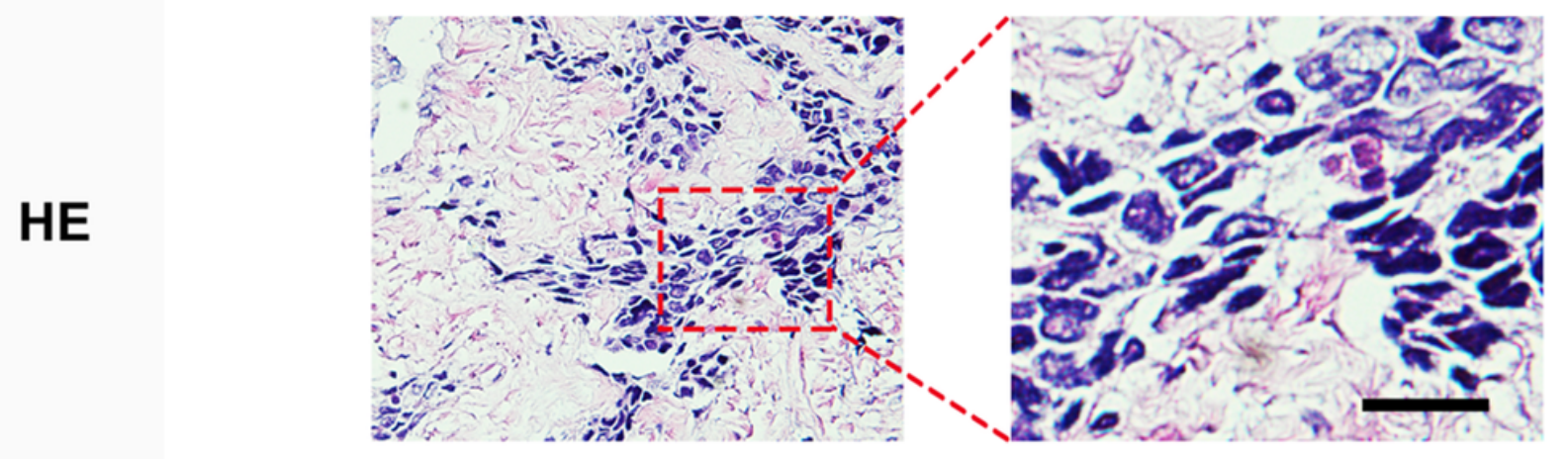

cytokeratin

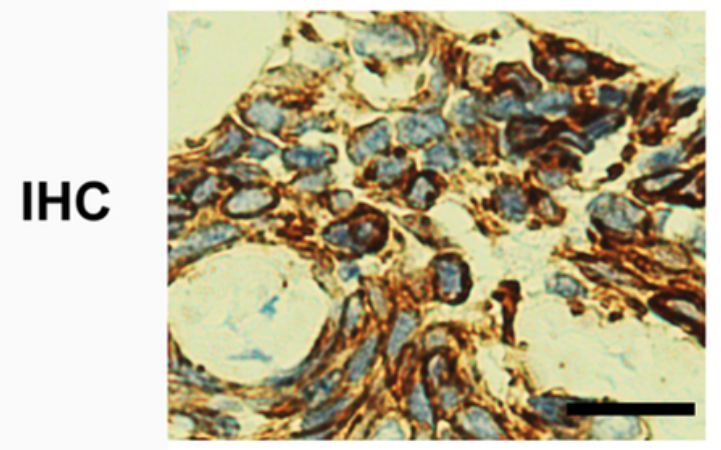

myogenin

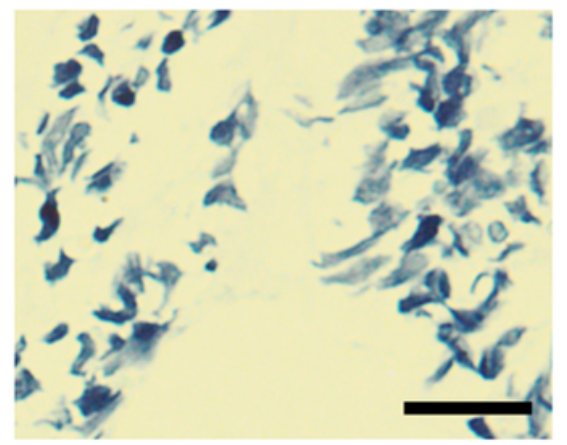

CD99

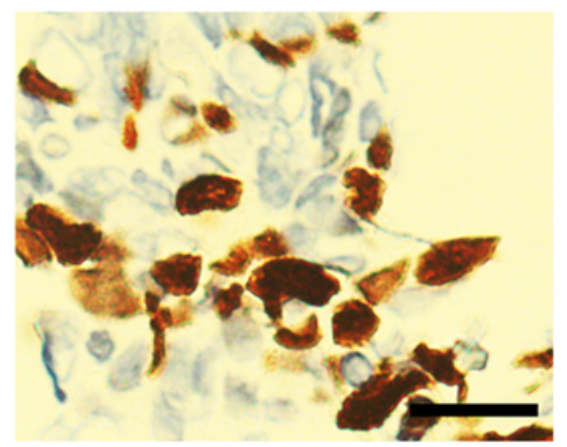

Figure 4

The pathology imaging in one representative case (A 19-year-old man with abdominopelvic cavity DSRCT). H\&E staining showed hyperchromatic nuclei and eosinophilic cytoplasm in cells. Immunohistochemistry showed cytokeratin (+), myogenin (-), and CD 99 (+). Error bar is $200 \mu \mathrm{m}$. 

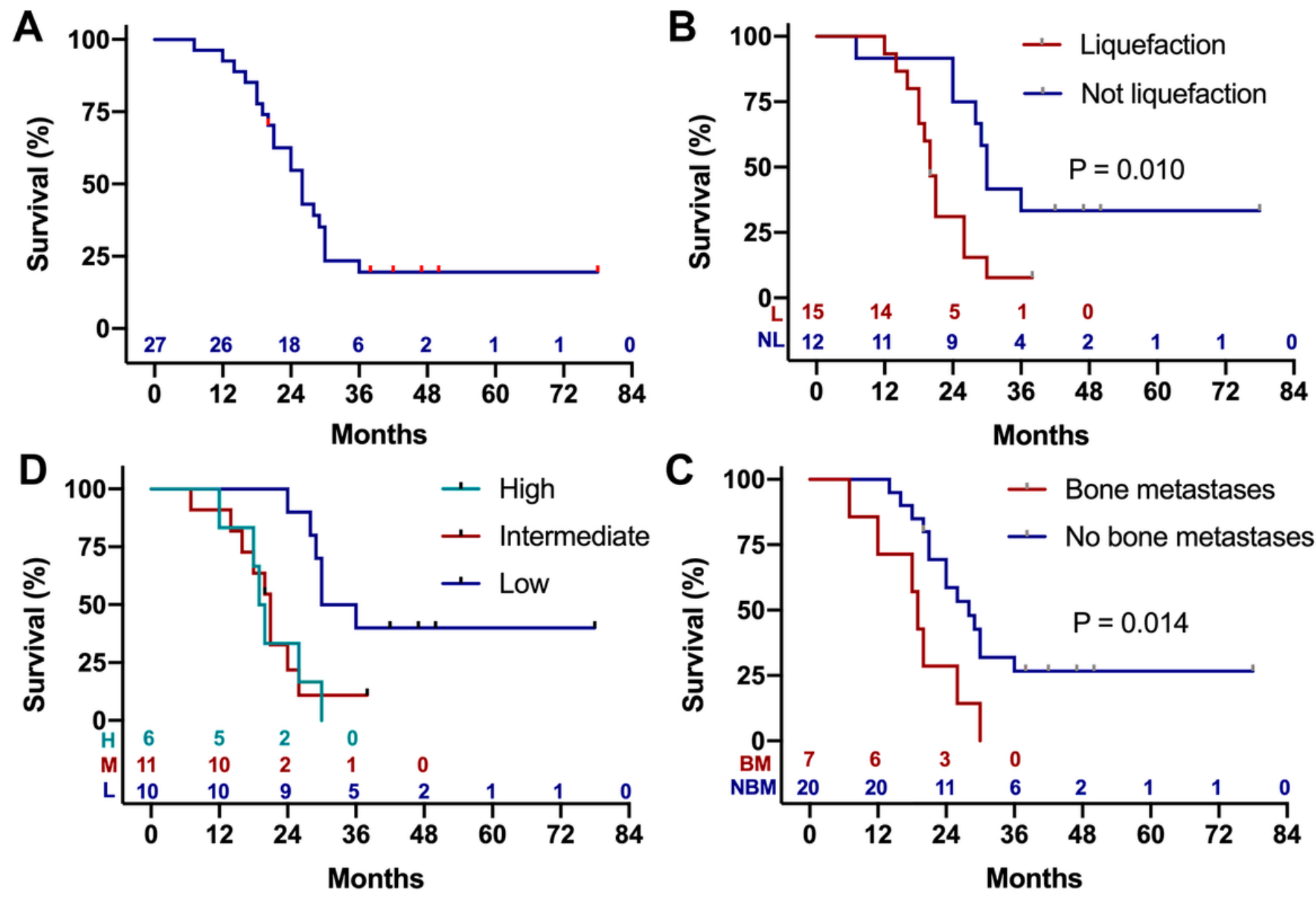

Figure 5

Kaplan Meier survival plots of overall survival (OS) for all patients after treatment, comparison between patients with and without liquefaction (B) and bone metastasis (C), and stratified analysis by risk staging system (D). 